\title{
DIGITALCOMMONS

\section{Predictors of Social Physique Anxiety in Elite Female Youth Athletes}

Jeffrey J. Martin

Wayne State University, aa3975@wayne.edu

Hermann J. Engels

Wayne State University

John C. Wirth

Wayne State University

Kari L. Smith

\section{Recommended Citation}

Martin, J. J., Engels, H.J., Wirth, J.C., \& Smith, K. (1997). Predictors of social physique anxiety in elite female youth athletes. Women in Sport and Physical Activity Journal, 6(1), 29-48.

Available at: http://digitalcommons.wayne.edu/coe_khs/35 
NOTICE IN COMPLIANCE WITH PUBLISHER POLICY: This is a reconstructed and formatted version of an article originally published in Women in Sport \& Physical Activity Journal, 6(1), 1997, 29-48. Copyright @ 1997 Women of Diversity Productions Inc./National Association for Girls and Women in Sport. Archived by permission. 


\title{
Predictors of Social Physique Anxiety in Elite Female Youth Athletes
}

\author{
Jeffrey J. Martin, Hermann J. Engels, John C. Wirth, and Kari L. \\ Smith
}

\begin{abstract}
The purpose of this study was to examine predictors of social physique anxiety (SPA). SPA, self-esteem, body-esteem, public body consciousness $(\mathrm{PBC})$ and percent body fat (\%BF) were assessed with elite female youth athletes $(N=68)$ competing in either figure skating, soccer or gymnastics. Stepwise multiple regression analyses, controlling for BF\%, accounted for $59 \%$ of the variance in SPA. Self-esteem entered first, and BF\%, followed by body-esteem and PBC. The psychological variables accounted for $57 \%$ of the variance with self-esteem contributing the most $(\mathrm{R}$ square change $=$ $45 \%$ ). Contrary to previous research, BF\% did not significantly contribute to SPA. Additionally, a MANOVA and follow- up ANOVA and Scheffe's tests revealed significant sport differences among SPA, self-esteem, and body-esteem.
\end{abstract}

How people present themselves to others is known as self presentation (Leary, 1992). A premise of Self presentation theory is that individuals seek to enhance favorable impressions, and minimize unfavourable reactions, from others (Leary, 1992). Individuals who are ineffective in managing their impressions, or anticipate being ineffective, may experience social anxiety (Leary, 1983). A subtype of social anxiety, social physique anxiety (SPA), is experienced when people feel, or anticipate feeling, that their bodies are being devalued (Hart, Leary, \& Rejeski, 1989).

In exercise settings, the body is both salient and important. Thus, the social context of exercise may promote SPA. To assess SPA, Hart and colleagues (1989) developed the social physique anxiety scale (SPAS). Both Hart et al. (1989) and Leary (1992) proposed that self presentation and SPA are important features of exercise and sport.

Self presentation theory, and specifically SPA, have been useful in explaining exercise related cognition, affect, and behavior (Crawford \& Eklund, 1994; Eklund \& Crawford, 1994; Spink, 1992). Crawford and Eklund (1994) found that college women high in SPA were not attracted to a video of an exercise setting where aerobic dance clothing was worn. 


\section{J. J. Martin, H. J. Engels, J. C. Wirth, and K. L. Smith}

High SPA women, however, expressed a positive attitude when the same video participants wore clothing de- emphasizing the body. In a follow up investigation, Eklund and Crawford (1994) found that, similar to Hart et al. (1989), SPA was positively related to percent body fat (\% BF). Furthermore, women who exercised for weight control reasons reported greater SPA compared to women who exercised for other reasons (Eklund \& Crawford, 1994). Both \% BF and exercising for weight control reasons accounte for $39 \%$ of the variance in SPA. Spink (1992) found that women high in SPA preferred to exercise in private, as opposed to public, and suggested that high SPA women may avoid evaluative settings (i.e., exercise clubs) which might heighten SPA. Cumulatively, from these findings we suggest that women's exercise behaviors may be influenced by feelings of SPA.

In contrast to college aged women, McAuley and Burman (1993) studied adolescent female gymnasts. They found that athletes lower in self-presentation confidence and physical self-efficacy tended to experience SPA, and supported the importance that expectancy constructs play in relation to SPA. In brief, SPA is a psychological construct worthy of examination. However, both Eklund and Crawford (1994) and McAuley and Burman (1993) cited the need to examine self- referent based theoretical antecedents of SPA such as self-esteem, body-esteem, and selfefficacy because few researchers have done this. Therefore, to address this need, we examined four potential predictors of SPA as suggested by previous investigators.

Body-esteem, or people's evaluations of their bodies, has a significant influence on self-esteem (Harter, 1993; Lerner, Karabenick, \& Stuart, 1973; Rohrbacker, 1973; Rosen \& Ross, 1968). Since positive relationships between body-esteem and self-esteem in adolescent girls (Folk, Pederson, \& Cullari, 1993; Kenealy, Gleeson, Frude, \& Shaw, 1991) and college students (Secord \& Jourard, 1953) have been found, this means that individuals who are pleased with their bodies tend to have positive selfesteem compared to people less pleased with their bodies. Based on these results, it is logical to expect that individuals who dislike their bodies (i.e., have low body-esteem) may be prone to SPA. Furthermore, the relationship between body- esteem and self-esteem may be indicative that self-esteem may also be related to SPA. People with low self-esteem may be more likely to experience SPA. Therefore, we examined both self and body-esteem as potential antecedents of SPA

However, body-esteem is considered multidimensional (Franzoi \& 


\section{Predictors of Social Anxiety}

Shields, 1984; Wright \& Whitehead, 1987). For instance, perceptions of physical attributes (other than weight) such as muscle development or physical conditioning may impact significantly on body and self-esteem in athletic populations (Fox \& Corbin, 1989; Franzoi \& Shields, 1984). Additionally, Wright and Whitehead (1987) propose that negative perceptions related to weight are closely tied to both body and self-esteem. Presumably, athletes dissatisfied with their weight and/or physical condition would be prone to SPA. Therefore, we employed a multidimensional measure of body-esteem that allowed subjects to report both feelings about their weight and physical condition (Franzoi \& Shields, 1984).

Control theory (Carver \& Scheier, 1981) indirectly suggests that body awareness may be related to SPA (Fenigstein, Scheier, \& Buss, 1975; Miller, Murphy, \& Buss, 1981). Public self-consciousness (awareness of the public aspects of ones' self) is positively related to social anxiety (Carver \& Scheier 1981) and SPA (Hart et al., 1989). Thus, we propose that public body consciousness (PBC: awareness of the public aspects of ones' body), a more physique specific form of awareness compared to public selfconsciousness, would be positively related to SPA, a body specific form of social anxiety. In other words, athletes aware of their bodies may be prone to SPA. Based on this reasoning, we examined PBC as a potential predictor of SPA.

Body-esteem is also negatively related to objective body weight (Folk et al., 1993) and \%BF (Huddy, et al., 1993). Similarly, \%BF is positively related to SPA (Eklund \& Crawford, 1994; Hart et al., 1989). Thus, we assessed \%BF to determine if self-esteem, body-esteem, and PBC would account for variance in SPA beyond that attributable to \% BF.

Finally, we examined elite female youth athletes for the following reasons First, it is generally more important for females, compared to men, to present an attractive physique and females report greater SPA than males (Hart et al., 1989; Isogai, 1995; Snow \& Harris, 1986). Second, because females are often critical of their bodies, SPA should be a meaningful construct to investigate with girls (Phelps et al., 1993). Third, we examined gymnasts and figure skater because the potential to experience SPA is presumably high due to the importance of presenting an attractive, yet athletic, physique in order to score well in competition. Last, we were interested in elite athletes as few researchers examining SPA have focused on elite competitors. We studies soccer players on the 
premise that self-presentation of the body is unimportant to soccer performance. Thus, comparing soccer players to figure skaters and gymnasts may provide further insight into SPA and body related cognitions.

In summary, our first purpose was to examine potential predictors of SPA. We hypothesized that self-esteem and perceptions of physical condition and weigh would be negatively related to SPA whereas \% BF and PBC would be positively correlated with SPA. Because of the exploratory nature of the current study, we did not predict which variables may be most strongly related to SPA. Based on the Eklund and Crawford (1994) study, we expected the psychological predictors to account for variance above that attributable to $\% \mathrm{BF}$.

Our second purpose was to examine potential sport differences in the variables assessed. Due to the exploratory nature of this aspect of the study, we did not formulate any a priori hypotheses with the exception that for reasons explicated above, we expected gymnasts and figure skaters to report higher SPA compared to soccer players.

\section{Method}

\section{Subjects}

Over a 3 year period, sixty-eight, experienced $(M=8.1 \mathrm{yrs}, S D=2.7)$ elite female youth soccer players $(n=24)$, figure skaters $(n=35)$ and gymnasts $(n=9) 9$ to 17 years of age, $(M=13.3, S D=2.2)$ participated in the present study. Soccer players were designated as elite because they had been selected for the United States Olympic Development Program or had won the state soccer championship. Figure skaters were considered elite because they had all qualified for the national championships. Gymnasts were classified as elite for their age group because they were all rated 8 or higher on a 0 (lowest ranking) to 10 (highest ranking) scale used by the United States Gymnastics Federation to rank gymnasts.

\section{Instruments}

Social Physique Anxiety Scale (SPAS). The SPAS developed by Hart et al. (1989) are used to assess the degree to which people feel anxious from the perception that their bodies are being devalued by others. Subjects respond to 12 items based on the degree to which the items are true for 


\section{Predictors of Social Anxiety}

them and obtain scores ranging from 12 to 60 . Higher scores are indicative of greater SPA. The 5-point Likert scale is anchored by 5 (extremely) and 1 (not at all). An example of one question from the SPAS is "In the presence of others, I feel apprehensive about my physique/figure." Item 2 ("I would never worry about wearing clothes that might make me look too thin or overweight") which is negatively worded, was altered to reflect a positive statement, "I would worry about wearing clothes that might make me look too thin or overweight." The change in item 2 was made based on the recommendation of Eklund, Mack, and Hart (1996) as well as other research (Lantz, Hardy, \& Ainsworth, 1991; McAuley \& Burman, 1993; Petrie, Diehl Rogers, \& Johnson, 1996) where the negative wording led to confusion and low item to total correlations. Adequate internal consistency $(r=.90)$, predictive validity, and construct validity have been documented (Crawford \& Eklund, 1994; Hart et al., 1989; McAuley \& Burman, 1993). The present study demonstrated adequate internal consistency with an alpha of .87 and item to total correlation ranging from .26 to .74. Although researchers (Cramer-Hammann, Lutter, Corneluis, Piontek, \& Hardy, 1993) have questioned the unidimensionality of the SPAS, only this past year, in a factorial validity study of 1760 females, have researchers suggested that a model with two first-order factors subordinate to one factor is best (Eklund, Mack, \& Hart, 1996). Thus, similar to previous research using the SPAS, we used the total SPAS score representing the higher order single factor.

Self-Esteem (SE). Rosenberg's (1965) self-esteem inventory is a 10 item scale with scores ranging from 1 (strongly disagree) to 4 (strongly agree). Total scores range from 10 to 40 with higher scores indicative of more favorable self-esteem. An example of an item is "On the whole, I am satisfied with myself." Adequate internal consistency $(r=.92)$, test-retest reliability $(r=.85)$ and convergent and discriminant validity have been demonstrated (Wylie, 1974). An alpha coefficient of .87 and item to total correlations (ranging from .52 to .69) were evidence of adequate internal consistency.

Body-Esteem (BE). The Body-Esteem Scale (Franzoi \& Shields, 1984) has three subscales to assess sexual attractiveness, physical condition (PC), and weight concern (WC). Only the latter two subscales were used in the present study. Subjects responded to nine and ten words or phrases for the PC and WC subscales, respectively. Scores range from 1 (have strong 
negative feelings) to 5 (have strong positive feelings). Total scores range from 9 to 45 and 10 to 50 for PC and WC subscales, respectively. Higher scores reflect more favorable feelings about the body dimension in question. An example of one item from the PC subscale is "Physical Stamina" and for the WC subscale, "Waist." Adequate internal consistencies have been demonstrated for both the PC $(r=.82)$ and the WC $(r=.88)$ subscales (Franzoi \& Shields, 1984). In the present investigation, we found adequate internal consistencies with alpha coefficients of .89 (item to total $=.56$ to .75$)$ and .88 (item to total $=.49$ to .72) for the PC and WC, respectively.

Body Consciousness Questionnaire (BCQ). The Body Consciousness Questionnaire was developed by Miller et al. (1981) to assess individuals' awareness of their bodies. Although the BCQ has 3 subscales, only the Public Body Consciousness (PBC) subscale was used in the current study. The PBC subscale reflects subjects' awareness of observable aspects of their bodies. A question from this subscale is "I think a lot about my body build." Subjects respond to 6 items for the PBC subscale by answering from 0 (extremely uncharacteristic) to 4 (extremely characteristic) based on the degree to which the items are true for them. The total score can range from 0 to 24 with higher scores indicative of a greater consciousness or awareness of the body. Test-retest reliability $(r=.73)$, discriminant validity, and construct validity have been demonstrated (Miller et al., 1981). In the current study adequate internal consistency was achieved with an alpha of .79 and item to total correlations ranged from .33 to .69 .

Percent Body Fat (\%BF). Hydrostatic weighing was used to determine body density $(\mathrm{Db})$ by using four calibrated load cells to measure underwater weight (Buskirk, 1961). Repeated underwater weighing trials were performed for each subject until three consistent underwater weights were obtained. The average of these three weights was used as the criterion value. Residual lung volume used in the $\mathrm{Db}$ computation was estimated as $28 \%$ of vital capacity (Wilmore, 1969). \%BF was calculated from $\mathrm{Db}$ using standard age and gender specific equations (Lohman, 1989).

\section{Procedures}

Prior to testing, parents gave informed consent for their children. Athletes received packets containing a letter describing the purpose of the study, 


\section{Predictors of Social Anxiety}

human subject consent forms, a demographic questionnaire (i.e., age, gender, years of playing experience), and the previously described instruments.

\section{Results}

Alpha coefficients for each scale were adequate to achieve internal consistencies (Cronbach, 1951; Nunnally, 1978) and can be found in Table 1 with means, standard deviations, and score ranges.

Table 1. Means, standard deviations, ranges and althp coefficients for SPA, SE, PC, WC, PBC, and \%BF of Elite female athletes, age 9-17 years.

\begin{tabular}{|c|c|c|c|c|}
\hline & Mean & StanDev & Range & Alpha \\
\hline SPA & 29.3 & 8.8 & $15-51$ & 0.87 \\
\hline SE & 31.9 & 4.3 & $21-40$ & 0.87 \\
\hline PC & 36.0 & 5.5 & $24-45$ & 0.89 \\
\hline wC & 34.3 & 7.5 & $10-50$ & 0.88 \\
\hline PBC & 17.7 & 3.2 & $6-24$ & 0.79 \\
\hline$\% B F$ & 15.8 & 5.7 & $3.8-31.6$ & -- \\
\hline
\end{tabular}

Note: $\mathrm{SE}=$ Self-esteem; $\mathrm{PC}=$ Physical Condition; $\mathrm{WC}=$ Weight Concern; SPA $=$ Social Physique Anxiety; $\mathrm{PBC}=$ Public Body Consciousness; \%BF = Percent Body Fat. Alpha = Coefficient for internal consistency.

A MANOVA was conducted to determine if there were differences in the psychological variables and $\% \mathrm{BF}$ as a function of sport type. Because the multivariate $\mathrm{F}(1,66)=2.5, p<.01$, was significant, an ANOVA was conducted for each psychological construct and \%BF. Significant differences among sport type were found for self-esteem $[\mathrm{F}(2,65)=6.15, p$ $<.01]$, SPA $[\mathrm{F}(2,65)=4.89, p<.01]$, physical conditioning $[\mathrm{F}(2,65)=5.26, p$ $<.01]$ and weight concern $[\mathrm{F}(2,65=4.14, p<.05]$. Both $\mathrm{PBC}$ and $\% \mathrm{BF}$ 
approached significance $(p<.06)$.

To determine where the differences existed among the three sport types for the four variables examined, Scheffe' tests were conducted. Because multiple tests were conducted, we used the Scheffe' test, a conservative procedure, which limits the probability of type I errors (Cramer, 1994). The means and standard deviations for each variable by sport type can be found in Table 2 as well as significantly different means as determined by the Scheffe' test.

Table 2. Means and standard deviations by sport team for SPA. SE, PC, WC, PBC, and \%BF of elite female athletes age 9-17 years (Players $n=24$ ).

\begin{tabular}{llllll}
\multicolumn{2}{c}{ Soccer } & \multicolumn{2}{c}{ Skaters } & \multicolumn{2}{c}{ Gymnasts } \\
\hline Mean & SD & Mean & SD & Mean & SD \\
\hline
\end{tabular}

$\begin{array}{lllllll}\text { SPA } & 32.0^{*} & 8.2 & 29.4 & 8.8 & 21.8^{*} & 6.3 \\ \text { SE } & 30.8 * & 3.8 & 32.7 & 4.7 & 36.4^{*} & 2.2 \\ \text { PC } & 37.8 & 4.1 & 34.9 * & 6.2 & 40.0^{*} & 4.3 \\ \text { WC } & 34.7 & 5.9 & 33.8^{*} & 8.2 & 41.0^{*} & 6.6 \\ \text { PBC } & 18.0 & 2.2 & 18.1 & 3.7 & 15.3 & 2.3 \\ \text { \%BF } & 17.7 & 5.7 & 15.1 & 4.8 & 13.0 & 7.4\end{array}$

Note: $\mathrm{SE}=$ Self-esteem; $\mathrm{PC}=$ Physical Condition; $\mathrm{WC}=$ Weight Concern; SPA $=$ Social Physique Anxiety; PBC = Public Body Consciousness; \%BF = Percent Body Fat.

* Significantly different means as determined by the Scheffe' test.

Soccer players reported significantly higher SPA $[\mathrm{F}(2.65)=4.89, p<.01]$ and lower self-esteem, $[\mathrm{F}(2,65)=6.15, p<.01]$ than gymnasts. Gymnasts reported more favorable perceptions of their physical condition $[\mathrm{F}(2,65)=$ $5.26, p<.05]$ and weight $[\mathrm{F}(2,65)=4.14, p<.05]$ compared to skaters. Table 
Predictors of Social Anxiety

3 contains correlations among the variables tested.

Table 3. Pearson Product Moment Coorelations among SPA, SE, PC, WC, PBC, and \%BF for elite female athletes age 9-17 years.

\begin{tabular}{lccccc}
\hline & \multicolumn{1}{c}{$\mathrm{SE}$} & $\mathrm{PC}$ & $\mathrm{WC}$ & $\mathrm{PBC}$ & $\% \mathrm{BF}$ \\
\cline { 2 - 6 } $\mathrm{SPA}$ & $-.68 * *$ & $-.33^{* *}$ & $-.53 * *$ & $.35 * *$ & .15 \\
SE & & $.27 *$ & $.39 * *$ & -.14 & -.18 \\
$\mathrm{PC}$ & & & $.72 * *$ & -.08 & -.06 \\
WC & & & & -.21 & -.11 \\
PBC & & & & & .14 \\
\hline
\end{tabular}

Note: SPA = Social Physique Anxiety; SE = Self-esteem; $\mathrm{PC}=$ Physical Condition; $\mathrm{WC}=$ Weight Concern; PBC = Public Body Consciousness; \%BF = Percent Body Fat.

${ }^{* *} p<.01 ;{ }^{*} p<.05$

Self-esteem, physical condition, and weight concern were negatively associated with SPA whereas PBC was positively associated with SPA. Surprisingly, and contrary to our hypothesis, \%BF was unrelated to SPA. To provide information regarding the relative contributions of each psychological variable towards predicting SPA, a stepwise multiple regression was conducted after entering \%BF first. Although the correlation $(r=72)$ between weight concern and physical condition might have been an indication of multicollinearity, variance inflation factors (VIF) and tolerance figures for variables in the equation were acceptable (Berk, 1977; Tabachnick \& Fidell, 1989).

As seen in Table 4, self-esteem clearly contributed to most of the variance in SPA. Weight concern and PBC contributed to a lesser degree. Cumulatively, we were able to account for $57 \%$ of the variance in SPA.

Table 4. Final Summary Table of Stepwise Regression Analysis Examining Predictors of SPA Controlling BF\% for elite female 
J. J. Martin, H. J. Engels, J. C. Wirth, and K. L. Smith

athletes age 9-17 years.

\begin{tabular}{|c|c|c|c|c|}
\hline & $\begin{array}{l}\text { Prediction } \\
\text { of SPA }\end{array}$ & $\begin{array}{l}\text { Beta R } \\
\text { sq }\end{array}$ & $\begin{array}{l}\text { Adj R } \\
\text { sq }\end{array}$ & $\begin{array}{l}R \text { sq } \\
\text { change }\end{array}$ \\
\hline & \multicolumn{4}{|c|}{ Forced Entry } \\
\hline \multirow[t]{2}{*}{ Step $1 \% B F$} & .15 & .02 & .00 & .02 \\
\hline & \multicolumn{4}{|c|}{ Stepwise Entry } \\
\hline Step 2 SE & $-.68 * *$ & .47 & .45 & .45 \\
\hline Step 3 WC & $-.31 * *$ & -.55 & .53 & .08 \\
\hline Step 4 PBC & $.21 *$ & .59 & .57 & .04 \\
\hline
\end{tabular}

Note: $\mathrm{SPA}=$ Social physique anxiety; $\mathrm{SE}=$ Self-esteem; $\mathrm{WC}=$ Weight concern; $\mathrm{PBC}=$ Public body consciousness; \%BF = Percent body fact. ${ }^{* *} p<.01 ;{ }^{*} p<.05$

\section{Discussion}

Our first purpose was to predict SPA. According to the results, athletes with low self-esteem, unfavorable perceptions of their weight and with a heightened awareness of the public aspects of their body were most susceptible to experiencing SPA. Self-esteem, a global psychological construct, accounted for most of the variance in SPA. Weight concern and PBC contributed $8 \%$ and $4 \%$ of the variance, respectively, towards predicting SPA and entered after self-esteem which accounted for $45 \%$ of the variance. Thus, for this sample of young elite female athletes, low global feelings of self-worth were a major predictor of feelings of SPA. Concern about weight and awareness of the minimally improve the predictability of SPA.

Given the high value and pervasiveness of ideal body images, particularly for females (Brenner \& Cunningham, 1992; Snow \& Harris, 1986), the consistent relationships among self and body-esteem (Harter, 1993; Rosen \& Ross, 1968; Secord \& Jourard, 1953) and self-presentational concerns (Leary, 1992), it isn't unexpected to discover a self-esteem and 


\section{Predictors of Social Anxiety}

social physique anxiety relationship.

However, the mechanism behind the self-esteem/SPA relationship in this study is unclear. To explain the strong $(r=.70--.80)$ and positive physical appearance/self-esteem relationship often found in research, Harter (1993) argue that because perceptions of physical appearance are salient, consistently on display, and elicit evaluative reactions from others as early as infancy, they become intricately woven into ones' global selfesteem. Thus, it is plausible that athletes' negative body-related cognitions (i.e., WC, PC) have become incorporated into their self-esteem. As a result, self-esteem is more strongly related to SPA compared to body specific cognitions.

Contrary to previous research, \%BF was unrelated to SPA. The relatively low mean \% $\mathrm{BF}$ is not unexpected for this sample of elite athletes' low mean \% BF and low mean SPA scores however, may have limited our ability to detect a $\% \mathrm{BF} / \mathrm{SP}$ relationship. Previous researchers reporting relations between $\% \mathrm{BF}$ and SPA have examined college aged women with greater average \%BF and higher mean SPA (Crawford \& Eklund, 1994; Eklund \& Crawford, 1994; Hart et al., 1989). These researchers reported mean $\% \mathrm{BF}$ ranging from $22 \%$ to $32 \%$ and mean SPA scores ranging from 37.31 to 40.12 . In contrast, our sample means were 15.8 and 29.3 for \% BF and SPA, respectively.

Relationships among the predictor variables also warrant discussion. For example, the strong correlation between weight concern and physical condition is an indication that subjects satisfied with their physical condition were also likely to be satisfied with their weight. The significant, albeit small to moderate, correlations between self-esteem and weight concern $(r=.39)$, and physical condition $(r=.27)$ may mean that subjects with unfavorable views of their bodies i.e., low body-esteem also tended to have lower feelings of self-worth.

We also found differences among the psychological variables examined, although due to the small sample sizes we suggest caution in interpreting these results. Gymnasts were higher in self-esteem and lower in SPA compared to soccer players. Additionally, gymnasts had more favorable perceptions of their weight and physical conditioning compared to skaters. Thus, as a group, the gymnasts reported the most favorable self-perceptions.

The SPA results are somewhat surprising given that gymnasts, 


\section{J. J. Martin, H. J. Engels, J. C. Wirth, and K. L. Smith}

similar to skaters, were thought to be the athlete group most susceptible to experiencing SPA. However, compared to McAuley and Burmans' (1993) sample of gymnasts, the gymnasts in the current study were substantially lower in SPA ( $M=21.8$ vs. $M=40.3)$. In fact, contrary to the previous researchers who suggest these athletes may be at risk for heightened levels of SPA (Folk et al., 1993; McAuley \& Burman 1993), this group of athletes reported low SPA (see Table 2). Of course, the small number of gymnasts $(n=9)$ compared to the McAuley and Burman (1993) study $(n=$ 236) "warrants extreme caution."

It is important to note that the total sample and sport type sample descriptive statistics (see Tables 1 and 2) are indicative, in addition to low SPA, participants reported favorable self-esteem, weight concern and physical condition perceptions. Two important factors may help explain this group's overall positive profile.

First, the current sample represents an elite group of young girls who have been successful in sport. Thus, the favourable self-referent cognitions reported here bay be the result of high levels of fitness and successful sport experiences. Second, limiting socio-cultural influences may not yet be operating. For example, societal attitudes denigrating the appropriateness of athletic excellence for young women may not be fully operating until mid-adolescence which is still a few years away for most of the sample (McCabe et al., 1991). Additionally, potentially troublesome identity issues associated with a changing body image as the result of puberty may not be active (Harter, 1993; McCAbe et al., 1991). Puberty, and specifically menarche, typically occurs around the age of $13(\mathrm{M}=12.8$, SD 1.2) for most young girls (Rogol, 1988) and significantly later for both experienced figure skaters $(M=15.2)$ and gymnasts $(M=15.3)$ (wells \& Plowman, 1988). Because of the current sample's age $(M=13.3, S D=2.2)$ and sport experience $(\mathrm{M}=8.1, \mathrm{SD}=2.7)$ characteristics, many athletes may not have begun puberty. While somewhat speculative, the above two explanations are tenable given the developmental stages and eliteness of the current sample.

In summary, highlights of the current study include the following. First, feelings of self-esteem played a significant role in these athletes' experience of SPA. Additionally, unfavorable perceptions of weight and heightened awareness of observable aspects of their bodies also contributed to increased SPA. Second athletes reported strong self-referent based cognitions. In particular, gymnasts reported the most favorable 


\section{Predictors of Social Anxiety}

profile.

Future researchers using longitudinal data spanning puberty may provide insight into SPA. For example, predictors of SPA may fluctuate with changes related to developmental process (i.e., puberty, \%BF, lean body mass, etc.). Longitudinal data of this nature should be valuable in determining how and why SPA is experienced by young females.

Finally, the purpose of this study was to examine predictors of SPA. According to social cognitive theory (Bandura, 1986) makes clear, cognitive and social factors, such as SPA, self-esteem, and body-esteem, exert reciprocal influences. Thus, it is important to recognize, in addition to our findings, that the experience of SPA may also contribute to reduced body and self-esteem.

\section{References}

Bandura, A. (1986). Social foundations of thought and action: A social cognitive theory. Englewood Cliffs, NJ: Prentice Hall.

Berk, K.N. (1977). tolerance and condition in regression computations. Journal of American Statistical Association, 72, 863-866.

Brenner, J.B., Cunnigham, J.G. (1992). Gender differences in eating attitudes, body concept, and self-esteem among models. Sex Roles, 27, 413-437.

Buskirk, E., R. (1961). Underwater weighing and body density: A review of procedures. In J. Brozek \& A. Henschel (Eds.), Techniques for Measuring Body Composition, Washington, DC: National Academy of Sciences.

Carver, C.S., Scheier, M.F. (1981). Attention and self-regulation: A control theory approach to human behavior. New York: Springer-Verlag.

Cash, T.F. (1990). the psychology of physical appearance: asthetics, attributes, and images. In T.F. Cash \& T. Pruzinsky (Eds.), Body images: Development, deviance, and change. New York: Guilford. pp. 5259 .

Cramer, D. (1994). Introducing statistics for social research. New York : Routledge.

Cramer-Hammann, B., Lutter, C., Corneluis, A., Piontek, K., \& Hardy, C.J. (1993). Understanding the factor structure of the social physique anxiety scale. Poster session presented at the annual meeting of the Association for the Advancement of Applied Sport Psychology, 


\section{J. J. Martin, H. J. Engels, J. C. Wirth, and K. L. Smith}

Montreal, Quebec, Canada.

Crawford, S., \& Eklund, R.C. (1994). Social physique anxiety, reasons for exercise, and attitudes towards exercise settings. Journal of Sport and Exercis Psychology, 17, 70-82.

Cronbach, L.J. (1951). Coefficient alpha and the internal structure of tests. Psychometrika, 17, 297-334.

Eklund, R.C., \& Crawford, S. (1994). Active women, social physique anxiety and exercise. Journal of Sport and Exercise Psychology, 17, 431448.

Eklund, R.C. Mack, D., \& Hart, E. (1996). Factorial validty of the Social Physique Anxiety Scale for females. Journal of Sport and Exercise Psychology, 18, 281-295.

Fenigstein, A., Scheier, M., \& Buss, A.H. (1975). Public and private self consciousness: Assessment and theory. Journal of Consulting and Clinical Psychology, 43, 522-527.

Folk, L., Pedersen, J., \& Cullari, S. (1993). Body satisfaction and selfconcept of third and six-grade students. Perceptual and Motor Skills, 76, 547- 553.

Fox, K.R., \& Corbin, C. B. (1989). The physical self-perception profile: Development and preliminary validation. Journal of Sport and Exercise Psychology, 11, 408-430.

Franzoi, S. L., \& Shields, S. A. (1984). The body esteem scale: Multidimensional structure and sex differences in college population. The Journal of Personality Assessment, 48, 173-178.

Hart, E.A., Leary, M.R., \& Rajeski, W.J. (1989). The measurement of social physique anxiety. Journal of Sport and Exercise Psychology, 11, 94-104.

Harter, S. (1993). Causes and consequences of low self-esteem in children and adolescents. In R.F. Baumeister. (Ed.), Self-esteem: The puzzle of low self-regard, (pp, 87-116). NY: Plenum.

Huddy, D.C. Nieman, D. C., \& Johnson, R.L. (1993). Relationship between body image and percent body fat among college male varsity athletes and nonathletes. Perceptual and Motor Skills, 77, 851-857.

Isogai, H. (1995, June 16). Gender differences in social physique anxiety. Paper presented at the annual meeting of the North American Society for the Psychology of Sport and Physical Activity. Pacific Grove, CA.

Kenealy, P., Gleeson, K. Frude, N., \& shaw, W. (1991). The importance of the individual in the "causual" relationship between attractiveness and self-esteem. Journal of Community and Applied Social Psychology, 1, 45-56. 


\section{Predictors of Social Anxiety}

Lantz, C., Hardy, C., \& Ainsowth, B. (1991). The effects of social physique anxiety, gender, age, and depression on excercise behavior. Paper presented at the annual meeting of the Association for the Advancement of Applied Sport Psychology in Savannah, GA.

Leary, M.R. (1992). Self-presentational processes in exercise and sport. Journal of Sport and Exercise, 14, 339-351.

Leary, M.R. (1983). Understanding social anxiety. Beverly Hills, CA: Sage.

Lerner, R. M., Karabenick, S.A., \& Stuart, J.L. (1973). Relations among physical attractiveness, body attitudes, and self-concept in male and female college students. The Journal of Psychology, 85, 119-129.

Lohman, T.G. (1989). Assessment of body composition in children. Pediatric Exercise Science, 1, 19-30.

McAuley, E., \& Burman, G. (1993). The Social Physique Anxiety Scale: Construct validity in adolescent females. Medicine and Science in Sport and Exercise, 25, 1049-1053.

McCabe, A.E., roberts, B.T., \& Morris, T.E., (1991). Athletic activity, body image, and adolescent identity. In L. Diamant. (Ed.), Mind-body maturity: Psychological approaches to sports, exercise and fitness, (pp. 91103). NY: Hemisphere Publishing Co.

Miller, L.C., Murphy, R., \& Buss, A.H. (1981). Consciousness of body: Private and public. Journal of Personality and Social Psychology, 41, 397406.

Nunnally, J.C. (1978). Psychometric Theory (2d ed.) New York: McGraw-Hill

Petrie, T,A., Diehl, N., Rogers, R.L., \& Johnson, C.L. (1996). The Social Physique Anxiety Scale: Reliability and construct validity. Journal of Sport an Exercise Psychology, 18, 420-425.

Phelps, L., Johnston, L.S., Jimenez, D.P., Wilczenski, F.L., Andrea, R.K., \& Healy, R.W. (1993). Figure preference, body dissatisfaction, and body distortion in adolescence. Journal of Adolescent Research, 8, 297-310.

Rogol, A.D., (1988). Pubertal development in endurance-trained female athletes. In E.W. Brown and C.F. Branta (Eds.), Competitive sports for children and youth (pp. 173-193). Champaign, IL: Human Kinetics.

Rohrbacker, R. (1973). Influence of a special camp program for obese boys on weight loss, self-concept, and body image. The Research Quarterly, 44, 150- 157.

Rosen, G.M., \& Ross, A.O. (1968). Relationship of body image to selfconcept. Journal of Consulting and Clinical Psychology, 32, 1.

Rosenberg, M. (1965). Society and the adolescent self-image. Princeton, NJ: Princeton University Press. 
Secord, P., \& Jourard, S. (1953). The appraisal of body-cathexis: Bodycathexis and the self. Journal of Consulting Psychology, 17, 343-347.

Snow, J.T., \& Harris, M.B. (1986). An analysis of weight and diet content in five women's interest magazines. Journal of Obesity and Weight Regulation, 5, 194-214.

Spink, K.S. (1992). Relation of anxiety about social physique to location of participation in physical activity. Perpetual and Motor Skills, 74, 10751078.

Tabachnick, B., \& Fidell, L. (1989). Using multivariate statistics. New York: Harper \& Row.

Wells, C.L., \& Plowman, S.A. (1988). Relationships between training, menarche, and amenorrhea. In E.W. Brown and C.F. Branta (Eds.), Competitive sports for children and youth, (pp. 195-2193). Champaign, IL: Human Kinetics.

Wilmore, J. (1969). The use of actual, predicted and constant residual volumes in the assessment of body composition by underwater weighing. Medicine and Science in Sport, 1, 87-90.

Wright, E. J., \& Whitehead, T.L. (1987). Perceptions of body size and obesity: a selected review of the literature. Journal of Community Health, 12.

Wylie, R.C. (1974). The self-concept (vol 1): A review of methodological and measuring instruments $(2 d$ ed.). Lincoln, NB: University of Nebraska Press. 